This item was submitted to Loughborough's Research Repository by the author.

Items in Figshare are protected by copyright, with all rights reserved, unless otherwise indicated.

\title{
Microstrip patch antennas with 3-dimensional substrates
}

PLEASE CITE THE PUBLISHED VERSION

http://ieeexplore.ieee.org/

PUBLISHER

Loughborough University (@ IEEE)

VERSION

AM (Accepted Manuscript)

LICENCE

CC BY-NC-ND 4.0

REPOSITORY RECORD

Whittow, W.G.. 2019. "Microstrip Patch Antennas with 3-dimensional Substrates". figshare.

https://hdl.handle.net/2134/11523. 
This item was submitted to Loughborough's Institutional Repository (https://dspace.lboro.ac.uk/) by the author and is made available under the following Creative Commons Licence conditions.

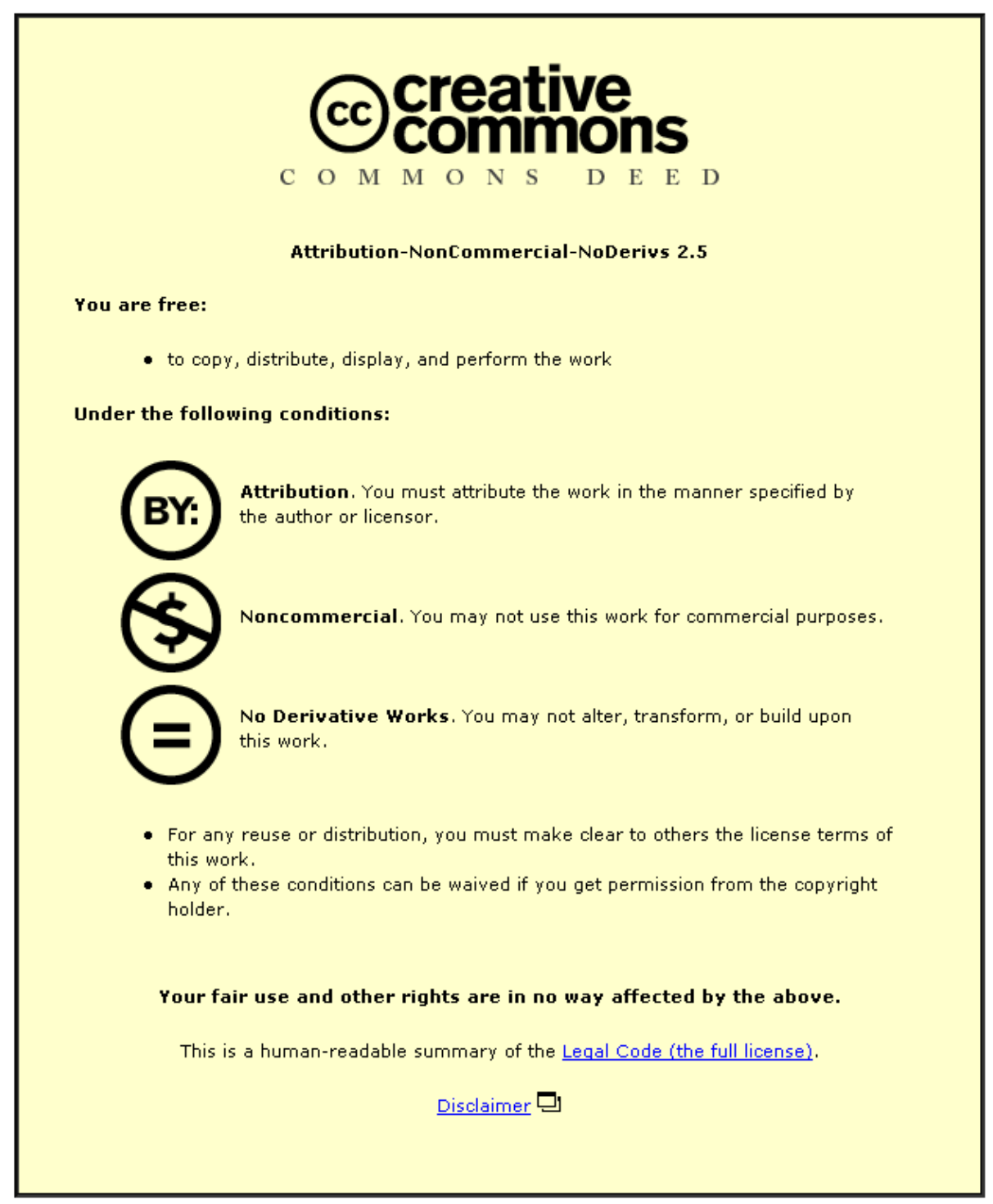

For the full text of this licence, please go to: http://creativecommons.org/licenses/by-nc-nd/2.5/ 


\title{
Microstrip Patch Antennas with 3-Dimensional Substrates
}

\author{
William G. Whittow ${ }^{\# 1}$ \\ ${ }^{\#}$ School of Electronic, Electrical and Systems Engineering, Loughborough University, LE11 3TU, UK \\ ${ }^{1} \mathrm{w} \cdot \mathrm{g} \cdot$ whittow@lboro.ac.uk
}

\begin{abstract}
This paper investigates the concept of replacing conventional flat 2-D patch antennas with 3-D versions where the substrate height is not uniform. The hypothesis of this work is that the electric fields are not evenly distributed under the patch and hence increasing the height in specific locations can be beneficial in terms of size of performance.
\end{abstract}

\section{INTRODUCTION}

We live in a world where people want 24-7 connectivity and we want this without the inconvenience of having wires. This means that antennas are essential to our quality of life. Consumers demand that new technology is smaller, lighter, can transmit more information, uses less battery power and look aesthetically attractive. Furthermore, we must consider smaller ground planes, more complex operating platforms and interferences from nearby electronics. These design pressures are then passed onto antennas designers. As the antenna size is related to the wavelength, it is not straight forward to continually miniaturize the antenna and increasingly innovative techniques are being considered to address this. This paper will consider the idea of optimizing the 3-D shape of the substrate.

Microstrip patch antennas are popular because they are intuitive to design, have a ground plane which shields the antenna and have a hemispherical pattern. Professors Jim James and Peter Hall have created a large body of work on this topic [1-9]. This work has since been extended by other authors [10-13]. The size of the patch antenna cab be reduced by using shorting pins; shorting walls; slots; ceramic materials; fractals and folded patches and ground planes [1418].

There is an inherent trade-off between antenna size, bandwidth and efficiency [19-22]. It is common knowledge that increasing the height of a microstrip antenna increases the efficiency and bandwidth. Other methods of increasing the bandwidth include parasitic elements; stacked patches and Uslots [23].

The electric fields are not uniformly distributed underneath the patch antenna and this enables the material composition of the substrate to be optimised and can lead to electromagnetic advantages. The term 'textured dielectrics' was coined by Professor Volakis and his colleagues at Ohio University and refers to a substrate where the permittivity is varied as a function of location [24-27]. In this work, holes were cut into the substrate and different materials were manually inserted to create heterogeneous substrates. This laborious process increased the bandwidth by matching the low permittivity regions to areas with high electric fields. Previously, it was shown that a high bandwidth, high gain and low specific absorption rate (SAR) antenna can be created by matching the permittivity and permeability of the substrate [28] which provides further evidence that optimising the substrate can be advantageous.

In a related area, the author of this paper is considering manufacturing antenna systems with heterogeneous substrates using emerging nanotechnology fabrication processes [2933].

The concept of 3-D substrates may be particularly relevant to wearable antennas [34][35]. It is also hypothesized that the use of 3-D substrates may reduce the specific absorption rates (SAR) in the body [36].

\section{GEOMETRY}

The patch antennas in this paper were simulated using EMPIRE XCcel finite-difference time-domain (FDTD) software. The patch was designed to resonate at $2.4 \mathrm{GHz}$. The dimensions used were as follow: width in $X$ axis $=41.39 \mathrm{~mm}$; length in $\mathrm{Y}$ axis $=49.41 \mathrm{~mm}$; substrate size $=80 \times 80 \mathrm{~mm}$; substrate height $=0.5 \mathrm{~mm}$; permittivity $=2.2$ and tan delta $=$ 0.0009. The patch was fed with a probe feed and the distance of the probe from the side of the patch was varied to obtain a good 50 ohm match.

The geometry and the electric fields are shown in Fig. 1. The figure demonstrates how the electric fields are not uniformly distributed below the patch. As expected the largest electric fields occur to the left and right hand sides of the substrate below the patch antenna. The electric fields are small along the central axis of the patch (parallel to the $\mathrm{Y}$ axis). The maximum surface currents occur where the electric fields are smallest. The surface currents decrease symmetrically as we move in the positive or negative $\mathrm{X}$ directions.

The substrate height was then increased in selected locations as shown in Fig. 2:- (a) two rectangular ridges at the edge of the substrate: $0.9 \mathrm{~mm}$ high $\times 4 \mathrm{~mm}$ wide $\times 49.41 \mathrm{~mm}$; 
(b) one rectangular ridges at the centre of the substrate: $0.9 \mathrm{~mm}$ high $\times 8 \mathrm{~mm}$ wide $\times 49.41 \mathrm{~mm}$; (c) one triangular ridge at centre: $2 \mathrm{~mm}$ high $\times 8 \mathrm{~mm}$ wide $\times 49.41 \mathrm{~mm}$; (d) flat continuous patch with central groove in ground plane: $1 \mathrm{~mm}$ deep $\times 8 \mathrm{~mm}$ wide $\times 49.41 \mathrm{~mm}$ and (e) flat continuous patch with two grooves in ground plane below edges of patch: $1 \mathrm{~mm}$ deep $\times 4 \mathrm{~mm}$ wide $\times 49.41 \mathrm{~mm}$. Note in (d) and (e) the patch antenna is continuous but has been drawn as a transparent object to show the grooves in the ground plane and the thickness of the ground was increased and therefore the grooves did not form holes in the ground plane. These grooves were then filled with the substrate material.
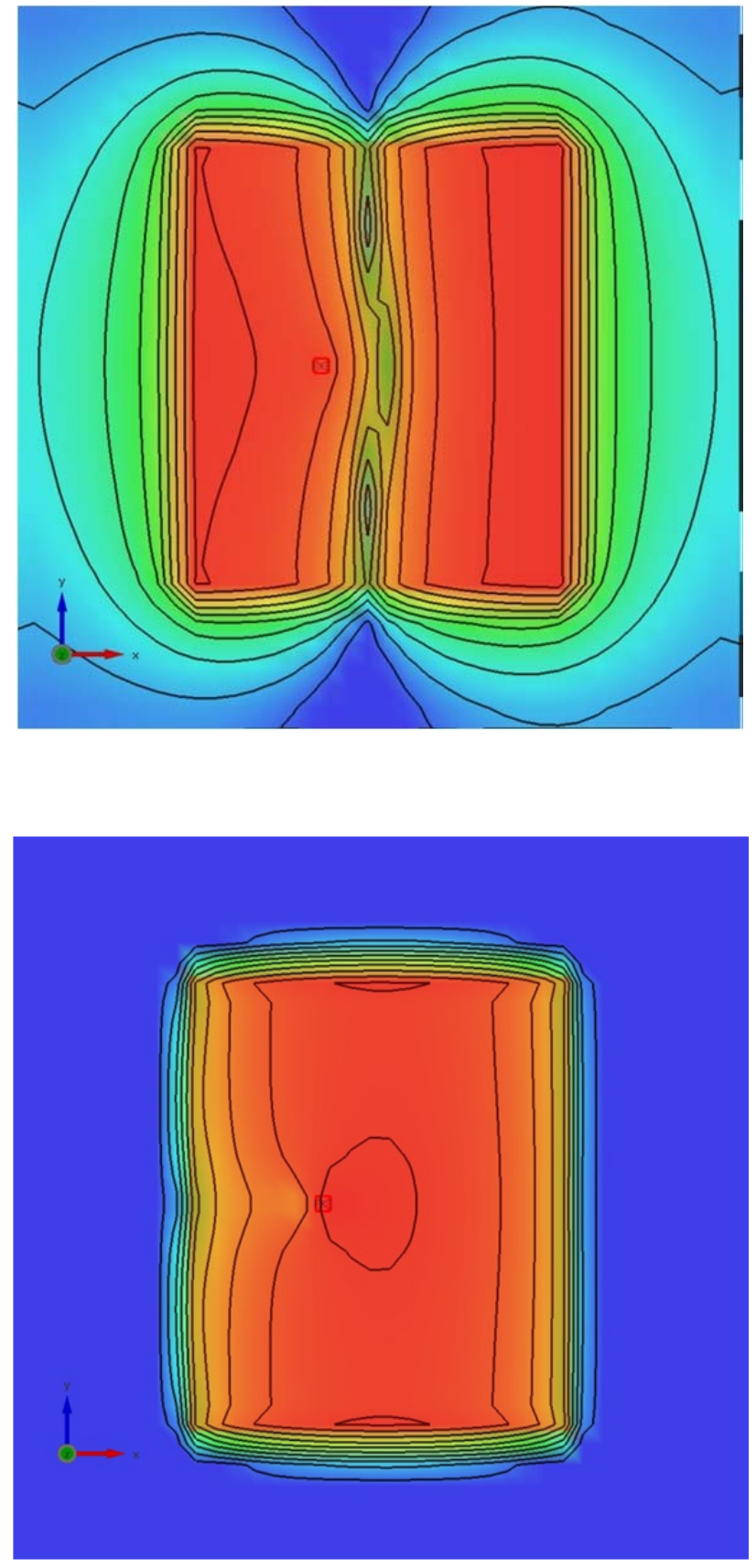

Fig. 1. Patch antenna with (a) electric fields in the substrate and (b) surface currents on the patch. 
(a)

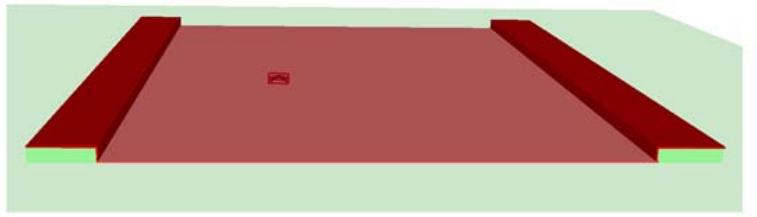

(b)

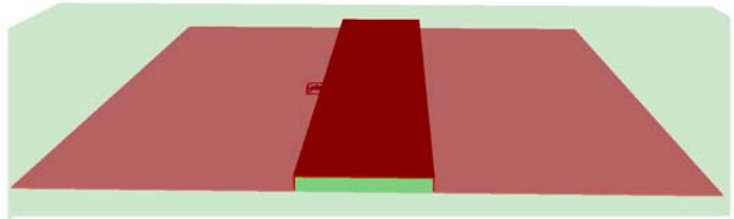

(c)

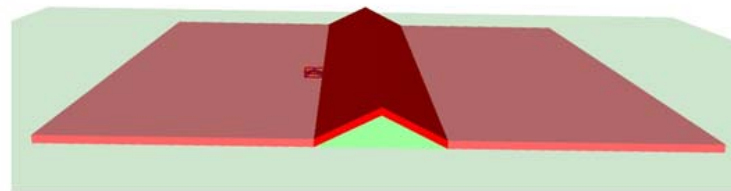

(d)

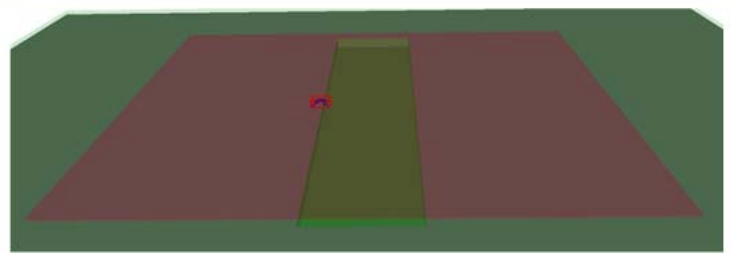

(e)

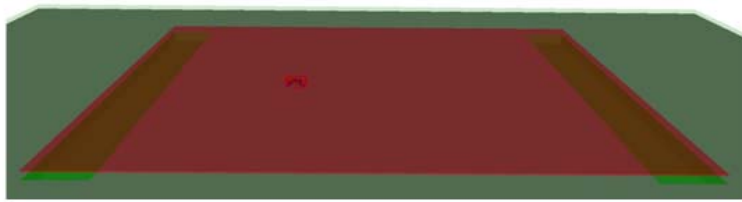

Fig. 2. Geometries of 3-D substrate. See Section II for more details.

\section{RESULTS}

The geometries in Fig. 2 were simulated. The original flat patch resonated at $2.37 \mathrm{GHz}$, see Fig. 3 . When ridges were added at the sides of the patch, the frequency increased. This is due to the step change in height not causing a continuous path for the currents. When the $8 \mathrm{~mm}$ ridge was placed at the centre of the patch, the frequency decreased to $1.82 \mathrm{GHz}$. Similar results were obtained with a triangular ridge at the centre of the patch. In these geometries, the patch had the same dimensions as seen from above and hence the total surface area of the patch is increased. An alternative method of increasing the local substrate height is to add a groove in the ground plane and thus the patch remains flat. This produced similar results to adding ridges in the substrate and indicates that the decrease in frequency observed with ridges at the centre of patch is due to the increased substrate height and not the increased surface area of the patch.

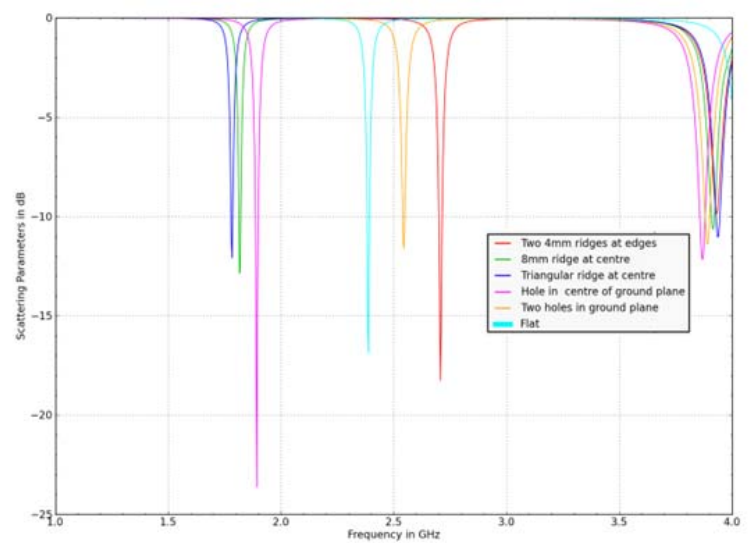

Fig. 3. The S11 results using the geometries in Fig. 2.

The frequency, bandwidth and efficiency results for the geometries in Fig. 2 are shown in Table 1. Note to allow a fair comparison these efficiency values do not include the return loss which can be improved by moving the feed position. The results indicate that the triangular ridge has an improved efficiency compared to the rectangular ridge at the centre. Furthermore, efficiency results were superior with the grooves in the ground plane compared to the ridges. This is due to currents preferring smooth contours as opposed to distinct boundaries.

Table 1. Frequency, bandwidth and efficiency for 3-D substrate geometries.

\begin{tabular}{|c|c|c|c|c|}
\hline Geometry & $\begin{array}{c}\text { Freq } \\
(\mathrm{GHz})\end{array}$ & $\begin{array}{c}\text { 10dB } \\
\text { BW } \\
(\mathrm{MHz})\end{array}$ & $\begin{array}{c}\text { Fractional } \\
\text { BW (\%) }\end{array}$ & $\begin{array}{c}\text { Efficiency } \\
(\%)\end{array}$ \\
\hline $\begin{array}{c}\text { Flat } \\
\text { 0.5mm } \\
\text { substrate }\end{array}$ & 2.39 & 11 & 0.46 & 53.8 \\
\hline Fig. 2 (a) & 2.71 & 15 & 0.55 & 41.3 \\
\hline Fig. 2 (b) & 1.82 & 8 & 0.44 & 43.3 \\
\hline Fig. 2 (c) & 1.79 & 7 & 0.39 & 74.3 \\
\hline Fig. 2 (d) & 1.89 & 14 & 0.74 & 67.3 \\
\hline Fig. 2 (e) & 2.54 & 9 & 0.35 & 59.0 \\
\hline
\end{tabular}

\section{CONCLUSIONS}

This paper has investigated the concept of designing antennas with 3-D substrates. The electric fields underneath the patch antenna are not uniformly distributed and hence increasing the substrate height in specific locations has been shown to be a more effective use of volume and materials. Increasing the substrate height where the electric fields are small and the currents are large reduced the frequency. The 
results have indicated that smooth transitions in the substrate shape will produce better results in terms of efficiency. This work is currently extended into a journal publication. The final version of this paper will be amended accordingly.

\section{REFERENCES}

[1] J. R. James, "Printed Antennas - New Research Frontiers," in Asia-Pacific Microwave Conference, APMC '92 , 1992, vol. 1, pp. 21-26.

[2] P. S. Hall, "The contribution of J R James to printed antennas," in The Second European Conference on Antennas and Propagation (EuCAP 2007) , 2007.

[3] K. Fujimoto, A. Henderson, K. Hirasawa, and J. R. James, Small Antennas . Research Studies Press , 1986.

[4] J. R. James and P. S. Hall, Handbook of Microstrip Antennas. IET, 1989.

[5] W. G. Whittow, M. I. Kitra, J. Vardaxoglou, C. J. Panagamuwa, P. McEvoy, and J. R. James, "Professor Jim James... great researcher and motivator in the field of antennas," in The Second European Conference on Antennas and Propagation (EuCAP 2007) , 2007.

[6] K. Fujimoto and J. R. James, Mobile Antenna Systems Handbook, vol. 2nd Editio. Nowood, MA, USA: Artech House, 2001

[7] J. R. James, P. S. Hall, and C. Wood, Microstrip Antenna Theory and Design. Peter Peregrinus Ltd, 1986.

[8] I. Morrow and J. Dahele, "A historical review on the research work of Professor Jim James,” in The Second European Conference on Antennas and Propagation (EuCAP 2007) , 2007.

[9] J. R. James, “Realising satcom antennas,” Electronics \& Communication Engineering Journal, vol. 10, no. 2, pp. 7382, 1998.

[10] A. Abdelaziz and D. Nashaat, "Compact GPS microstrip patch antenna," Journal of Theoretical and Applied Information Technology, vol. 4, no. 6, pp. 530-535, 2008.

[11] D. Guha and Y. Antar, Microstrip and Printed Antennas: New Trends, Techniques and Applications. Wiley, 2010.

[12] J. T. Rowley and R. B. Waterhouse, "Performance of shorted microstrip patch antennas for mobile communications handsets at $1800 \mathrm{MHz}$," Ieee Trans. Antennas and Propagation, vol. 47, no. 5, pp. 815-822, 1999.
[13] S. S. Holland, "Miniaturization of microstrip patch antennas for GPS applications (thesis)," Electrical and Computer Engineering. University of Massachusetts, Amherst, USA, 2008.

[14] J. W. Halloran, W. Liao, C. Chen, J. L. Volakis, J. S. Kula, and D. Psychoudakis, "Patch-Antenna Miniaturization Using Recently Available Ceramic Substrates,” vol. 48, no. 6, 2006.

[15] W. Chen and G. Wang, "Small size edge-fed sierpinski carpet microstrip patch antennas,” Electromagnetics, vol. 3, pp. 195-202, 2008.

[16] J. Huang, “A review of antenna miniturization techniques for wireless applications," in International Conference on Applied Electromagnetics and Communications Dubrovnik, Croatia, 2001.

[17] I.-K. Kim, J.-G. Yook, and H.-K. Park, "Fractal-shape small size microstrip patch antenna," Microwave and Optical Technology Letters, vol. 34, no. 1, pp. 15-17, Jul. 2002.

[18] R. L. Li, E. Tsai, G. Dejean, M. Tentzeris, and J. Laskar, “Small Folded Shorted-Patch Antenna,” pp. 0-3, 2000.

[19] H. A. Wheeler, "The radiansphere around a small antenna," IEE Proc., vol. 47, pp. 1325-1331, 1959.

[20] H. A. Wheeler, "Fundamental Limitations of Small Antennas,” Proceedings of the IRE, vol. 35, no. 12, pp. 1479-1484, 1947.

[21] S. R. Best, "A study of the performance properties of small antennas," in Antenna Applications Symposium, 2007, pp. pp. 193-211.

[22] L. J. Chu, "Physical limitations on omni-directional antennas," Journal of Applied Physcis, vol. 19, pp. 13691393, 1948.

[23] K. M. Lee, K. F, Luk, Microstrip patch antennas. Imperial College Press, 2011.

[24] D. Psychoudakis, Y. H. Koh, J. L. Volakis, and J. H. Halloran, "Design method for aperture-coupled microstrip patch antennas on textured dielectric substrates," Antennas and Propagation, IEEE Transactions on, vol. 52, no. 10, pp. 2763-2766, 2004.

[25] D. Psychoudakis, J. L. Volakis, W. Zach, and J. W. Halloran, "Cavity-Backed Miniature Wideband UHF Circular Polarized Antenna With Textured Dielectrics," Antennas and Propagation, IEEE Transactions on, vol. 54, no. 12, pp. 3586-3592, 2006.

[26] G. Kiziltas, D. Psychoudakis, and J. L. Volakis, “Topology design optimization of dielectric substrates for bandwidth improvement of a patch antenna," Antennas and 
Propagation, IEEE Transactions on, vol. 51, no. 10, pp. 2732-2743, 2003.

[27] C. Chen and J. L. Volakis, "Bandwidth broadening of patch antennas using nonuniform substrates," Microwave and Optical Technology Letters, vol. 47, no. 5, pp. 421-423, 2005.

[28] M. I. Kitra, C. J. Panagamuwa, P. McEvoy, J. C. Vardaxoglou, and J. R. James, "Low SAR ferrite handset antenna design," IEEE Trans Antennas and Propagation, vol. 55, no. 4, pp. 1155-1164, 2007.

[29] W. G. Whittow, C. C. Njoku, and Y. C. Vardaxoglou, "Patch Antennas with Heterogeneous Substrates and Reduced Material Consumption Enabled by Additive Manufacturing Techniques," in 2012 IEEE International Symposium on Antennas and Propagation and USNC-URSI National Radio Science Meeting, 2012.

[30] C. C. Njoku, W. G. Whittow, and Y. C. Vardaxoglou, "Effective permittivity of heterogeneous substrates with cubes in a 3D lattice," IEEE Antennas and Wireless Propagation Letters (Special Issue on Metamaterials), vol. 10, pp. 1480-1483, 2011.

[31] C. C. Njoku, W. G. Whittow, and J. C. Vardaxoglou, "Microwave antennas and heterogeneous substrates using nanomaterial fabrication techniques (Invited Paper)," in IEEE Tropical Conference on Antennas and Propagation in Wireless Communications (APWC 11), 2011.

[32] C. C. Njoku, W. G. Whittow, and J. C. Vardaxoglou, "Simulation Methodology for Synthesis of Antenna Substrates with Micro-scale Inclusions," IEEE Trans Antennas and Propagation, vol. 60, no. 5, pp. 2194-2202, 2012.

[33] C. C. Njoku, W. G. Whittow, and J. C. Vardaxoglou, "Comparative study of nanomaterials' effective properties using canonical formulations," in 2010 Loughborough Antennas \& Propagation Conference (LAPC), 2010.

[34] T. Kellomäki, W. G. Whittow, J. Heikkinen, and L. Kettunen, "2.45 GHz plaster antennas for health monitoring," in EuCAP 2009, 2009.

[35] L. Ma, R. Edwards, and W. G. Whittow, "A notched hand wearable ultra wideband W printed monopole antenna for sporting activities," in 2008 Loughborough Antennas \& Propagation Conference, 2008, pp. 401-405.

[36] C. J. Panagamuwa, W. Whittow, and R. Edwards, “A study of the validation of RF energy Specific Absorption Rates for simulations of anatomically correct head FDTD simulations and truncated DASY4 standard equipment measurements," in The First European Conference on Antennas and Propagation (EuCAP 2006), 2006. 